\title{
Brachydactyly type A7
}

INSERM

\section{Source}

INSERM. (1999). Orphanet: an online rare disease and orphan drug data base.

Brachydactyly type A7. ORPHA:93397

Brachydactyly type A7 (Smorg asbord type) is a form of brachydactyly that presents with the characteristic features of brachydactyly type A2 (shortening of the middle phalanges of the index finger and, sometimes, of the little finger) and type $D$ (shortening of the distal phalanx of the thumb) plus various additional features. 